\title{
MASS CAMPAIGNS AND THE INDIVIDUAL
}

\author{
by J. A. Kinnear Brown, B.Sc., M.D., M.R.C.S., D.T.M. \\ Specialist Leprologist, Uganda
}

Before the industrial revolution every tool and article of furniture was made by one individual for the use of another. Personality and pride were expressed in craftmanship which was designed specially to meet some individual need. Supply however could not equal demand. Mass production provided for the requirements of more and more individuals but in the process the craftsman disappeared. The individual consumer had to accept goods made to a common pattern in which design was influenced by the convenience of the manufacturer. Concentration on quantity equalised and often sacrificed quality.

Since the earlier days industry has become more flexible and adaptable. The expression "The consumer is always right" is indicative of this and the value placed on trademarks and individual attention emphasises that the individual is still an important unit of society. However impersonal the intermediate stages of manufacture, at one end is an individual who plans and designs and at the other an individual who has to be convinced.

The mass principle has been taken into medicine. Mass campaigns have a military reference but they differ fundamentally from crusades. The one is designed to crush all opposition, whereas the other will dispose inadequate forces, participation springing from conviction. Participation even if it means martyrdom is as important to the individual as the outcome of battle. Not all the military crusaders were as divinely led as they thought, but the World owes much to the men and women who have wrestled with disease; with typhus, yellow fever and the many maladies that strike suddenly and fatally almost out of nowhere; workers wrestled even at the cost of their own lives. Some of the mass campaigns of today were made possible by the crusaders of yesterday, and if Gray were writing his Elegy afresh, he would no doubt wish to commemorate those individuals whose devotion was the foundation of medicine.

It is difficult to say which was the first mass campaign. Vaccination against small-pox was one of the most outstanding. Jenner's individual observations made it possible. It is no longer compulsory because with the reduced risk, it was thought safe to restore freedom to the individual. Its continuation depends on the education of the individual which in turn is often the responsibility of an individual physician.

The mass campaign against diphtheria needed little impulse when this disease was producing such a heavy mortality, but although this is of recent memory, the continuation of the campaign falls on 
the individual doctor in his contacts with the parents of young children. The assault on venereal disease has been pressed by every means but although its treatment is now simpler, it is essentially an individual matter requiring mutual understanding and secrecy. In the modern state, child welfare and marriage guidance clinics hinge on the personalities of those who conduct them. National Health Services make it easier for more people to get more medicine but their value is not to be measured by their cost, nor by the number of prescriptions or operations, but by the extent to which the individual practitioner meets the particular needs of the individual patient, retaining or restoring him as a useful member of society.

Medicine in the tropics includes a wider range of problems than more temperate climates. There are more diseases but less hospitals. Revenue is often unable to provide the minimum requirements. Sanitation is primitive or non-existent and there are few places with a piped sterile water supply. The greater part of the population is still illiterate and inaccessible to propaganda. It would be difficult to design countries with more natural difficulties for the health administrator, yet there is no more urgent necessity than that of better health if their peoples are to take their place in World affairs.

In Southern Nigeria in 1930 there was less than one doctor to 200,000 people. There are more to-day but not enough. In Uganda $95 \%$ of $\mathrm{jts}$ six million inhabitants have no other recourse than to hospitals staffed by less than 200 doctors. Although these figures are from different parts of Africa, they indicate the progress that has been made and the problem which lies ahead. The immediate answer is, of course, "Mass Campaigns" by which is meant any expedient which will prevent or cure disease on the widest possible scale at the least possible cost.

Mass campaigns have no single pattern; the one thing they have in common is their attempt to pit overwhelming force against disease, by dealing with the sources which give rise to it, the vectors that carry it, and the patients who contract it. As in war, there are no trimmings, and there is little time for the individual, but war against disease has one difference, which asserts itself later. Mass campaigns usually imply a large number of helpers treating a larger number of patients by routine methods and for reasons of urgency and economy the majority of the helpers have only a limited training. The success of the mass campaign depends on the attitude and conscientiousness of each helper, the total provision for each patient, and the response of each patient to what is provided. The individual at the centre may design and organise, but it is the individual at the periphery who controls the effectiveness of what has been planned.

Onchocerciasis is common in tropical Africa. It is transmitted by the Simulium fly, the larvae of which breed in the fast flowing waters of streams and rivers. It is responsible for much ill-health 
and disability and often leads to blindness. In that part of Uganda which borders the River Nile it had caused the evacuation of many people to healthier country. After ingenious and hazardous experiments the mass attack developed by the regular deposition in the river of a quantity of D.D.T. insecticide. This destroys the larvae and has made possible the return of the population to the fertile areas. Individual patients, however, remain to be treated if they are not to be an economic liability.

Schemes for malaria eradication have been undertaken in hyperendemic and resettlement areas. They have involved a threefold attack; on the breeding places of the vector, on the adult mosquitoes which infest the houses, and on the patients who harbour the parasite. The individual patients who have uncomfortably large spleens, severe secondary anaemia or other sequelae still remain and there is always the problem of the individual who has to be educated not to allow breeding places to redevelop through his ignorance or carelessness.

The introduction of the sulphones has created a tremendous change in the outlook in leprosy. Africa counts its patients by thousands and even millions. Here the problem is different as it is only the patient who has to be treated. He is the reservoir of infection, the carrier and the sufferer. Leprosy is most common in rural areas where the individual is remote from hospitals and inaccessible to those who wish to help him. He has to be sought and sought continually, for his treatment takes three years, or more. Many are disabled and cannot walk to hospitals every week. Those who try to do so in all weathers may develop trophic and traumatic ulcers in their feet, and their ultimate condition is then worse than their first. Mass campaigns are the most appropriate answer and take the form of treatment villages near to dispensaries where patients can live and farm and enjoy a communal life, or mobile clinics in which partly trained workers take medicine to clinics held under trees or in some temporary shelters using whatever form of transport is convenient, jeeps, bicycles, canoes or even camels. The progress which has been made is encouraging and the wider distribution of tablets is curing many patients. One can almost sit back and feel that here is the complete answer to one of the most publicised diseases of mankind. But is it? There are still problems associated with the individual and a great deal depends on the efficiency of the individual therapist.

The patient contracted his disease because he had an inherent susceptibility. He may have children some of whom have the same trait, fruitful soil for the bacillus should they encounter it. The drawback to the mass distribution of medicine over such a prolonged period is that the patient has to have initiative to continue his treatment. For one reason or another he may decide to cease treat- 
ment before he is cured and by this irregularity produce a drug resistant strain of bacillus. This may take years to develop in such a chronic disease, or years to discover, but there is evidence to suggest that it happens. There is really no obvious reason why the leprosy bacillus should not become resistant, nor why in this respect sulphones should be different from other drugs. The mass campaign may therefore give a false sense of security if it is content only to distribute tablets when patients attend and if it includes no follow up of the individual and his family, particularly of those whose treatment has been erratic or self-discontinued. The mass campaign may achieve a rapid reduction in the number of obvious patients but what if it leads to a drug resistant type of leprosy among the previously unindentified susceptible stock? It would be wrong to delude ourselves that in all circumstances the mass campaign is the final answer. It is the obvious and most appropriate method but at some point the individual must be studied.

It is within the experience of most people that patients soon tire of any effort to obtain treatment unless as a result they feel better, look better and are accepted by society as being better. If their deformities are unrelieved and they cannot live like other people and if they are not accepted by society, they are just as likely to absent themselves from treatment, as to pursue a regime that interferes further with their liberty and inclinations. The mass campaign is hampered if it provides no treatment nor amelioration of their disability, no help for their reactions and complications, no appropriate education of the community. The campaign must therefore include hospitals and leprosaria to give individual treatment to those who need it and to train those who will be carrying out the campaign among the masses, so that they do more than distribute tablets to those who happen to attend. The individual therapist must have behind him whatever is necessary to establish mutual confidence and achieve the co-operation of the individual patient and society. The mass campaign may appeal to one's sense of the dramatic but to produce lasting results it must be prosecuted with the individual patient in mind by individuals who have more than a casual financial interest in what they are doing. If success is the outcome, mass campaigns will need to be replaced by other methods and the residue of patients will then be most conveniently dealt with in leprosaria, that is in residential farm colonies with hospital facilities. If there is a breakdown because the mass campaign is not sufficiently thorough for any reason at all, and a resistant type of disease is produced the leprosaria will be necessary for investigation and more specialised treatment. This is not to say that new leprosaria should be multiplied, but it would be folly to begin to knock them down or to burn our boats before we are quite sure that we are safely on the other side.

There is another aspect. Leprosy is a disease of susceptible 
people, and there is evidence that suggests there is an immunological relationship between infections caused by the acid-fast group of mycobacteria. The relationship is contained within the individual's response to invasion. This is of more than academic interest; it involves the general relationship of allergy, resistance, and immunity. It is by studying the differences and similarities in the responses of individuals to different antigens, vaccines, and natural infection that facts of wider application and import may be discovered. This the mass campaign by itself cannot undertake although it may provide the material for investigation; yet if it fails, the problem may have to be reassessed and overcome by immunological methods.

To conclude, the value of the mass campaign lies in the wideness of its attack. Its limitation is the ease with which the treatment of the individual may become superficial and erratic. It is essential in its conduct that indigenous helpers should be used who have not the educational background always to appreciate how much depends on them. As in other spheres the mass method may achieve quantitative satisfaction, but qualitatively its weakness is its lack of individuality. The individual patient is the unit who unconsciously controls the destiny of the campaign and the individual therapist trained or semi-trained must see and treat that unit as an individual patient who expects to be made as normal a member of society as possible. The individual patient and the individual who is a prospective patient may hold the key to other problems and the mass campaign should not restrict its activities to a uniform "take it or leave it" schedule. It should use every opportunity of discovering in what way those who contract leprosy differ from those who do not and how these differences can be resolved. In short the outcome of the mass campaign depends on the integrity, personality and assiduity of each individual participant, and on the confidence engendered in each patient that he is regarded and treated as an individual and not as just another member of a milling crowd or an elongated weekly queue.

\section{Summary}

Mass campaigns in medicine include smallpox, diphtheria, venereal disease, onchocerciasis, and malaria. In leprosy, mass campaigns are now very common, and have been made possible by the introduction of the sulphone drugs. In the tropics there is a further incentive to mass campaigns in the heavy incidence of disease and a shortage of money. However, mass campaigns in leprosy have a large element of expediency, and a dogmatic pursuit of them to the exclusion of everything else is wrong: we should always remember our duty to the individual and the task of his complete rehabilitation into society. So in addition to dispensaries and mobile teams for the administration of the sulphones there 
should be treatment villages and the retention of leprosaria. A large number of untreated patients with leprosy deformities will prejudice the whole campaign, as it will cause despondency and spread the depressing idea that the individual is of no importance. The mass campaign will not produce lasting results unless it is pursued with the individual in mind. It may fail also from the production of drug resistance, which is not at all impossible with the sulphones. So the mass campaign may have the good point of a wideness of attack but will always remain an expediency in so far as we do not do a good job for the patient in all aspects of his illness and his rehabilitation. 